\title{
Initial Investigation into Microbleeds and White Matter Signal Changes following Radiotherapy for Low-Grade and Benign Brain Tumors Using Ultra-High-Field MRI Techniques
}

\author{
(D).-G. Belliveau, DG.S. Bauman, (D) K.Y. Tay, DD. Ho, and (D) R.S. Menon
}

\begin{abstract}
BACKGROUND AND PURPOSE: External beam radiation therapy is a common treatment for many brain neoplasms. While external beam radiation therapy adheres to dose limits to protect the uninvolved brain, areas of high dose to normal tissue still occur. Patients treated with chemoradiotherapy can have adverse effects such as microbleeds and radiation necrosis, but few studies exist of patients treated without chemotherapy.
\end{abstract}

MATERIALS AND METHODS: Ten patients were treated for low-grade or benign neoplasms with external beam radiation therapy only and scanned within 12-36 months following treatment with a 7T MR imaging scanner. A multiecho gradient-echo sequence was acquired and postprocessed into SWI, quantitative susceptibility mapping, and apparent transverse relaxation maps. Six patients returned for follow-up imaging approximately 18 months following their first research scan and were imaged with the same techniques.

RESULTS: At the first visit, 7/10 patients had microbleeds evident on SWI, quantitative susceptibility mapping, and apparent transverse relaxation. All microbleeds were within a dose region of $>45 \mathrm{~Gy}$. Additionally, 4/10 patients had asymptomatic WM signal changes evident on standard imaging. Further analysis with our technique revealed that these lesions were venocentric, suggestive of a neuroinflammatory process.

CONCLUSIONS: There exists a potential for microbleeds in patients treated with external beam radiation therapy without chemotherapy. This finding is of clinical relevance because it could be a precursor of future neurovascular disease and indicates that additional care should be taken when using therapies such as anticoagulants. Additionally, the appearance of venocentric WM lesions could be suggestive of a neuroinflammatory mechanism that has been suggested in diseases such as MS. Both findings merit further investigation in a larger population set.

ABBREVIATIONS: $\mathrm{QSM}=$ quantitative susceptibility mapping; $\mathrm{R}_{2}{ }^{*}=$ apparent transverse relaxation; $\mathrm{RN}=$ radiation necrosis; $\mathrm{XRT}=$ external beam radiation therapy

External beam radiation therapy (XRT) is commonly used in Ethe treatment of many brain neoplasms. In benign and lowgrade neoplasms (meningiomas, neuromas, low-grade gliomas),

Received August 12, 2016; accepted after revision July 24, 2017.

From the Departments of Medical Biophysics (J.-G.B., G.S.B., R.S.M.), Oncology (G.S.B.), and Medical Imaging (K.Y.T.), University of Western Ontario, London, Ontario, Canada; Centre for Functional and Metabolic Mapping (J.-G.B., R.S.M.), Robarts Research Institute, London, Ontario, Canada; London Regional Cancer Program (G.S.B.), London, Ontario, Canada; and Department of Radiology (D.H.),

Woodstock General Hospital, Woodstock, Ontario, Canada.

This work was supported by the London Regional Cancer Program Catalyst Grant, the Canada Research Chairs Program, and the Canada Foundation for Innovation.

Please address correspondence to Ravi Menon, MD, Robarts Research Institute, Western University, 1151 Richmond St N, London, ON N6A 5B7, Canada; e-mail: rmenon@robarts.ca; @northernthrux

- Indicates open access to non-subscribers at www.ajnr.org

$\equiv$ Indicates article with supplemental on-line table.

http://dx.doi.org/10.3174/ajnr.A5395 safe maximal surgical resection combined with XRT is usually the standard of care. The prescribed dose is typically a course of $54-60$ Gy in 30 fractions using conformal delivery with techniques such as intensity-modulated radiation therapy. These dose plans attempt to follow specific guidelines such as Quantitative Analysis of Normal Tissue Effects in the Clinic (http://www.aapm. org/pubs/QUANTEC.asp) to limit the dose to radiosensitive areas, including the uninvolved brain, brain stem, optic nerve, and optic chiasm, ${ }^{1}$ as well as the hippocampus, which is known for its role in neurogenesis. ${ }^{2,3}$ Due to the infiltrative nature of some neoplasms such as low-grade gliomas or the proximity of tumors to normal brain in other neoplasms, even conformal radiation techniques can result in some volume of healthy tissue receiving radiation. The dose delivered to the normal brain can potentially cause long-term effects later in the patient's life.

Following XRT, there are numerous reports of clinical sequelae that are classified into acute, early-delayed, or late effects. ${ }^{4}$ 
Acute and early-delayed adverse effects are usually temporary and resolve spontaneously with minimal treatment or steroids. Late effects are typically much more severe because they cause permanent changes to the brain parenchyma, including radiation necrosis (RN), cavernous angiomas, and microbleeds, ${ }^{4}$ resulting in ongoing neurologic deficits.

$\mathrm{RN}$ is an adverse effect that may present a few years following XRT; however, it can occur as early as 6 months and as late as 10 years following XRT. In some patients, regions of RN may be small and do not produce symptoms. In others, progressive RN can be seen with detrimental effects on the patient's quality of life. ${ }^{5}$ Symptoms ranging from headaches and drowsiness to memory loss, seizures, and focal deficits have been documented. Treatments of RN vary from observation to steroids or antiangiogenic agents. ${ }^{6}$ In some patients, surgical resection is required to debulk necrotic areas to alleviate symptoms.

The exact cause of RN is not entirely understood, but the 2 main hypotheses developed in the past 50 years are related to vascular and glial damage. ${ }^{4}$ The vascular hypothesis suggests that radiation necrosis is secondary to an ischemic event due to small-vessel injury, while the glial hypothesis suggests that damage to the white matter precursor cells occurs during XRT. Recently, the potential role of the immune response following XRT has been documented, ${ }^{7,8}$ implicating neuroinflammation as another mechanism contributing to the development of RN.

In addition to frank $\mathrm{RN}$, microbleeds detected on imaging following XRT are a recent discovery. ${ }^{9,10}$ Generally, microbleeds are thought to be either small deposits of hemosiderin, which can be attributed to damage to the small vessels, ${ }^{11}$; or, following radiation, microbleeds have been shown pathologically to be areas of telangiectasia. ${ }^{12}$ Microbleeds may be indicative of future vascular disease such as stroke. ${ }^{13}$ Microbleeds indicate not only that more serious disease could occur in the future but also that the patient could be put at risk of serious intracranial bleeding if started on anticoagulants. ${ }^{14}$

Techniques such as SWI are becoming more prominent with higher magnetic field strengths available clinically (3T) or for research $(\geq 7 \mathrm{~T})$. These techniques make locating microbleeds increasingly easier due to the increased SNR, which makes increased resolution possible at higher magnetic fields, and the linear-withfield-enhancement of the paramagnetic effect of the hemosiderin deposits. However, the increased resolution can also lead to falsepositives in microbleed detection because small venous vasculature that runs parallel to the magnetic field can be misinterpreted as a microbleed. SWI, quantitative susceptibility mapping (QSM), and apparent transverse relaxation $\left(\mathrm{R}_{2}^{*}\right)$ have been previously shown to be extremely sensitive to the vasculature and hemosiderin-rich microbleeds. ${ }^{15-18}$ These techniques are also sensitive to white matter lesions, as shown in various multiple sclerosis studies. ${ }^{19,20}$ Previous work from Reichenbach et $\mathrm{al}^{21}$ estimated that these techniques are sensitive to venous vasculature of approximately $100-200 \mu \mathrm{m}$ in diameter.

Among patients with brain tumors, most studies to date have investigated microbleeds and radiation necrosis among patients who have high-grade neoplasms ${ }^{22,23}$; however, long-term RN studies in this patient population may be less feasible due to the shortened life expectancy of most patients with malignant gliomas and the difficulty in distinguishing treatment effects and tumor progression. Additionally, these studies involve patients treated with chemotherapy, which has been shown potentially to influence the number of microbleeds present in the brain ${ }^{10,24}$ and may confound the estimates of microbleeds due to radiation alone.

This initial feasibility study presents results that focus on imaging microbleeds and white matter imaging changes using SWI, $\mathrm{QSM}$, and $\mathrm{R}_{2}{ }^{*}$ on patients treated for benign or low-grade neoplasms with radiation alone. These patients have a longer overall survival following successful treatment and thus are at higher risk of eventually experiencing delayed adverse XRT effects. It was hypothesized that SWI, QSM, and $\mathrm{R}_{2}^{*}$ may be useful imaging techniques to detect late radiation changes among this patient population. The ability to detect such changes would then warrant a larger scale investigation for patients who might be at risk of longer term sequelae of their treatment (cognitive effects or focal brain injury).

\section{MATERIALS AND METHODS \\ Patient Recruitment}

The study was approved by the human subjects' research ethics board of the University of Western Ontario. Ten patients (2 men, 8 women) were recruited from our affiliated cancer program at the London Regional Cancer Program and were screened for eligibility by the treating radiation oncologist (G.S.B.). Eligibility requirements included patients who were older than 18 years of age with a Karnofsky Performance Scale score of $>60$ and were treated for benign or World Health Organization grade I or II brain neoplasms within 12-36 months of their recruitment for the study. Treatments for their neoplasms could have included surgical resection followed by radiation therapy or primary radiation therapy alone. As per protocol, patients underwent an initial imaging session at the time of enrollment and a second session 12-24 months later to detect any evolution in imaging changes.

\section{MR Imaging}

Patients were scanned on a 7T MR imaging machine. This scanner underwent an upgrade between visits for some of the patients. Preupgrade, an Agilent/Siemens 7T MR imaging scanner (Agilent, Santa Clara, California) with a 15-channel transmit/31-receive channel coil was used. Postupgrade, a Siemens 7T Magnetom Step 2.3 MR imaging scanner (Siemens, Erlangen, Germany) with an 8-channel transmit/32-receive channel coil was used. All patients had their initial scan performed on the preupgrade scanner. Three patients had their second visit on the preupgrade scanner, while 3 had their second visit on the postupgrade scanner. An anatomic T1WI was obtained (preupgrade: MPRAGE, 1-mm isotropic voxel, scan time of 5 minutes 45 seconds; postupgrade: MP2RAGE, 0.8-mm isotropic voxel, scan time of 8 minutes 26 seconds); and a CSF-attenuated magnetization-prepared FLAIR sequence (preupgrade: 1-mm isotropic resolution, scan time of 12 minutes 42 seconds; postupgrade: not acquired) was acquired for registration to clinical scans. A multiecho gradient-echo (preupgrade: multiecho gradient-echo, $1 \mathrm{~mm}$ in-plane resolution, 
$1.5-\mathrm{mm}$ sections, $\mathrm{TR}=40 \mathrm{~ms}, \mathrm{TE}=2.4 \mathrm{~ms}$, echo spacing $=3.3$ ms, echoes $=6$, flip angle $=13^{\circ}$, generalized autocalibrating partially parallel acquisition $=2.1$; postupgrade: multiecho gradientecho, $1-\mathrm{mm}$ in-plane resolution, $1.5-\mathrm{mm}$ sections, $\mathrm{TR}=40 \mathrm{~ms}$, $\mathrm{TE}=4.9 \mathrm{~ms}$, echo spacing $=4.5 \mathrm{~ms}$, echoes $=6$, flip angle $=13^{\circ}$, generalized autocalibrating partially parallel acquisition $=2$ ) sequence was acquired. A less sensitive form of imaging had to be used postupgrade due to vendor constraints on the number of transmit coils.

\section{Postprocessing}

The multiecho gradient-echo data set was acquired and postprocessed into SWI, $\mathrm{R}_{2}{ }^{*}$ and QSM maps using in-house software.

\section{QSM}

The implementation of QSM used a preconjugate gradient method $^{25}$ and was compared with QSM using the MEDI toolbox in Matlab (MathWorks, Natick, Massachusetts) ${ }^{17}$; however, the data from the preupgrade scanner was not optimized for MEDI processing. The algorithm uses the phase information that is temporally unwrapped over each echo with the background field contributions being removed with a Gaussian high-pass filter of 11 $\mathrm{mm}$ to produce the local frequency shift. The QSM image was calculated by performing the regularized inversion demonstrated in Reichenbach et al. ${ }^{21}$ Postupgrade data were run through both the preconjugate gradient and MEDI toolbox; however, only data from the preconjugate gradient method were analyzed using the postupgrade data.

\section{$\boldsymbol{R}_{\mathbf{2}}{ }^{*}$}

$\mathrm{R}_{2}^{*}$ was computed with a nonlinear least-squares monoexponential fit with a voxel spread function for correction. ${ }^{26}$

\section{SWI}

An 11-mm Gaussian high-pass filter was used to filter the phase and was fit with respect to TEs using a weighted nonlinear least-squares function to calculate the local frequency-shift map. A frequency mask of $15 \mathrm{~Hz}$ was then applied to an average magnitude image from all echoes to create an SWI using inhouse software. Finally, Matlab (MathWorks) was used to create a minimum-intensity-projection image through $7 \mathrm{~mm}(7$ sections) of the SWI.

\section{Dose Plan Overlay}

Treatment dose plan and planning CT and MRIs were retrieved and were registered to the research MR imaging with the FMRIB Linear Image Registration Tool (FLIRT; http://www.fmrib.ox. ac.uk). ${ }^{27}$ It was found beneficial to crop the CT simulator session to include only the head including just a few sections below the cerebellum from the CT and a T1WI without the use of skullstripping. The matching was determined to be within the error of the 3-mm dose grid. CERR (http://cerr.info/about.php) ${ }^{28}$ was used to export the dose plan.

\section{Radiographic Assessment}

Images (SWI, MPRAGE, and FLAIR) were reviewed by 2 boardcertified neuroradiologists (K.Y.T., D.H.) blinded to the history of the patient. Both radiologists reviewing the images indepen-

\begin{tabular}{|c|c|c|c|c|}
\hline Patient & $\begin{array}{c}\text { Visit } 1 \\
\text { Microbleeds }\end{array}$ & $\begin{array}{c}\text { Visit } 2 \\
\text { Microbleeds }\end{array}$ & $\begin{array}{c}\text { New } \\
\text { Microbleeds }\end{array}$ & $\begin{array}{c}\text { Resolved } \\
\text { Microbleeds }\end{array}$ \\
\hline 1 & 7 & 4 & 2 & 5 \\
\hline 2 & 5 & $x$ & Did not return & Did not return \\
\hline 3 & 4 & $x$ & Did not return & Did not return \\
\hline 4 & 0 & 0 & 0 & 0 \\
\hline 5 & 2 & 2 & 0 & 0 \\
\hline 6 & 2 & 0 & 0 & 2 \\
\hline 7 & 0 & 0 & 0 & 0 \\
\hline 8 & 0 & 0 & 0 & 0 \\
\hline 9 & 1 & $x$ & Did not return & Did not return \\
\hline 10 & 5 & $x$ & Did not return & Did not return \\
\hline
\end{tabular}

Note:- $\mathrm{X}$ indicates patient did not return

${ }^{a}$ All microbleeds occurred in areas of radiation of $>45 \mathrm{~Gy}$.

dently and in a group setting established what constituted a microbleed. The microbleeds on all images were counted, and images were further assessed for vasculature and white matter abnormalities.

Once identified, the microbleeds were manually segmented on the SWI with ITK-SNAP 1.6 (www.itksnap.org) ${ }^{29}$ for further analysis with $\mathrm{R}_{2}^{*}$ and QSM.

\section{RESULTS}

\section{Clinical Findings}

Ten patients consented to imaging and were enrolled in the study. The On-line Table provides a full description of their cases, treatment, and current clinical status. A Mini-Mental State Examination was performed at the first visit, and a mean score of 29/30 \pm 0.9 indicated that patients were cognitively intact at assessment. Patients were imaged at a mean of $26.7 \pm 7.5$ months following their treatment, and 6 of 10 patients returned for a second MR imaging between 12 and 24 months ( $17.3 \pm 7.3$ months) following their first MR imaging. Four patients did not return for this second scan. Two patients became ill for unrelated health reasons, 1 patient opted not to return for a second research scan, and 1 patient's low-grade glioma evolved into a malignant glioma, precluding investigational re-imaging.

\section{Radiologic Findings}

No gross abnormalities or venous vessel density discrepancies were observed on the SWI. One patient (patient 8) had a cavernous angioma that had been previously detected on conventional MR imaging before enrollment in this study.

\section{Microbleeds}

Six of 10 patients had microbleeds on the postradiation imaging. In all except 1 patient (patient 6), microbleeds occurred in areas of high dose (>45 Gy). Some microbleeds resolved between the initial and follow-up scans. The Table reports the full list of microbleeds. In all patients, microbleeds had an $\mathrm{R}_{2}{ }^{*}$ of $>80 \mathrm{sec}-$ onds $^{-1}$ and QSM values lower than $-0.25 \mathrm{ppm}$. Most microbleeds had halo artifacts on QSM as shown in Fig 1, which aided in their detection.

\section{White Matter Lesions}

Three patients had periventricular or lobar lesions on their T1WI and FLAIR images in the mid- (>30 Gy) to high-dose ( $>45 \mathrm{~Gy}$ ) 
regions, consistent with white matter changes reported after radiation therapy ${ }^{30,31}$ as shown in Figs 2-4.

\section{Current Clinical Status}

As shown in the On-line Table, most patients who enrolled in this study are clinically stable following treatment for their neoplasms. Aside from patient 10, who developed a glioblastoma, their symptoms are not directly related to their diagnosis or treatment.

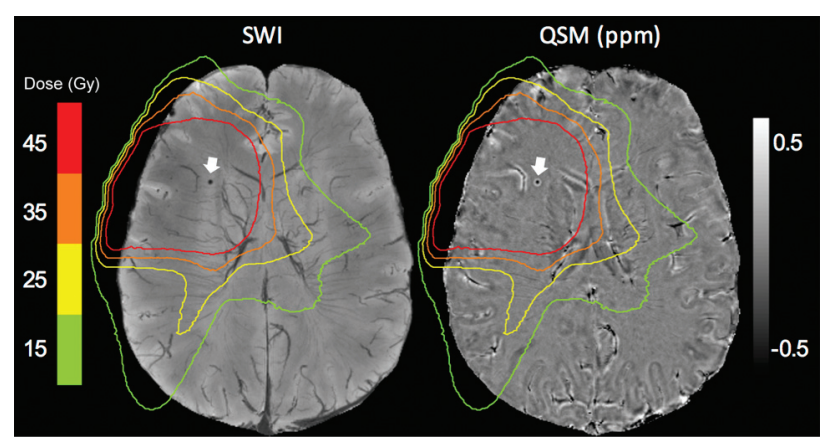

FIG 1. Patient 1 with microbleeds illustrated by the white arrow on SWI and QSM. Haloing artifacts can be seen on QSM. Venous vasculature is apparent in the high-dose region on SWI.

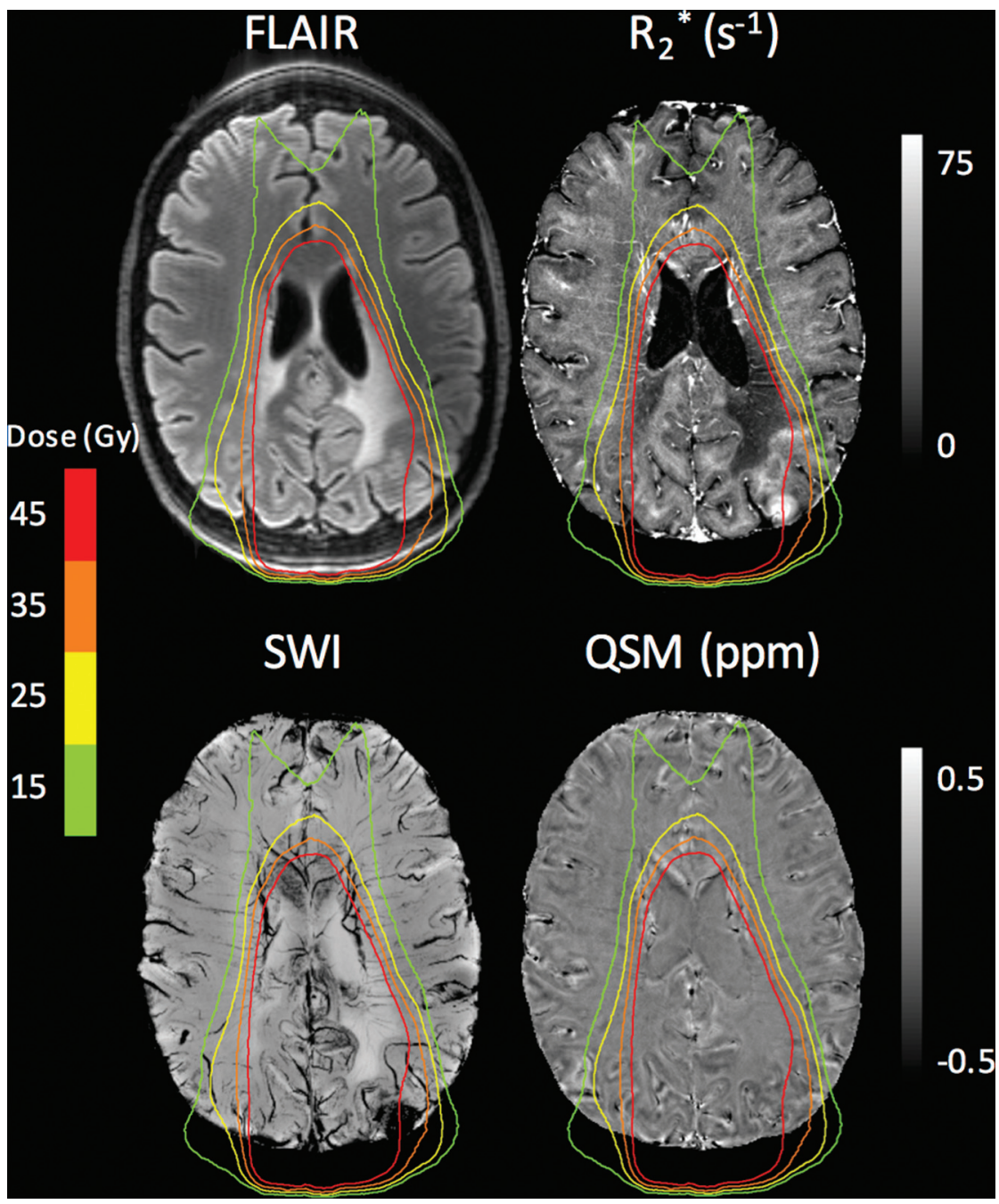

FIG 2. Patient 2 showing white matter abnormalities within the high-dose region as evidenced on FLAIR, $R_{2}{ }^{*}$, and SWI.

\section{DISCUSSION}

Searches of prior literature led us to believe that this is the first study that investigated vasculature and white matter changes with 7T MR imaging in patients treated for low-grade or benign neoplasms with radiation and an operation only. The potentially long survival of this patient population posttreatment increases the chance that they may experience late radiation adverse effects compared with patients with higher grade lesions. Imaging biomarkers that could identify patients at risk of delayed radiation sequelae could be useful in this patient population to refine radiation-delivery techniques and to explore mitigating strategies such as pharmacologic interventions. ${ }^{32}$

The focus of this study was to determine the feasibility of this technique being susceptible to late effects of XRT on the normal parenchyma (1-5 years after therapy). Gross abnormalities were not expected because these patients were clinically stable and monitored by conventional imaging, but it was hypothesized that it could be possible to detect subclinical lesions in the brain receiving high doses of radiation therapy. It is known that microbleeds have appeared in patients treated with chemotherapy or radiation therapy for high-grade neoplasms. ${ }^{10}$ Additionally, Liu et $\mathrm{al}^{17}$ demonstrated the ability to distinguish microbleeds from venous vasculature using quantitative methods. Therefore, an investigation into the occurrence of microbleeds and white matter signal changes as a potential imaging biomarker of late radiation effects in patients treated for low-grade brain neoplasms was performed. While some of the imaging indicated potentially demyelinating lesions based on the white matter signal changes, a clinical diagnosis was not possible.

In this cohort, 6 of 10 patients showed microbleeds within the highdose regions; and in 5 of 6 patients, no microbleeds were observed outside the high-dose region. Long-term follow-up is required to correlate with clinical end points such as future vascular incidents or cognitive adverse effects to determine whether microbleed monitoring could be important in these patients.

Although these patients do not have the frequency of microbleeds as shown in other studies of high-grade neoplasms, the appearance of microbleeds is indicative of endothelial damage within the high-dose region. This suggests the importance of long-term monitoring in this low-grade cohort because these patients could be at a higher potential for symptomatic vascular or cognitive changes later in life. ${ }^{33,34}$ The appearance of microbleeds could also indicate that further studies are required 


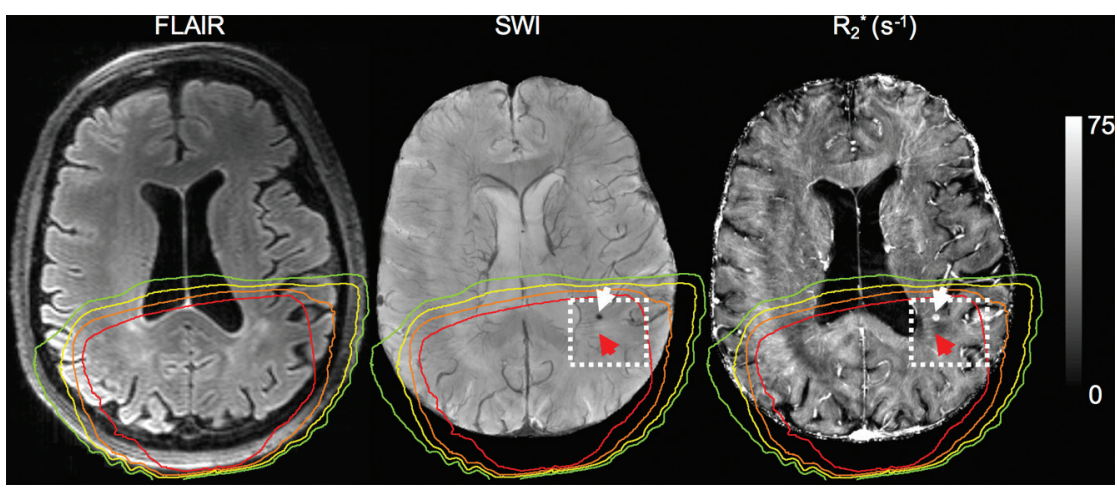

FIG 3. Patient 3 showing microbleeds on $\mathrm{SWI}$ and $\mathrm{R}_{2}{ }^{*}$ (white arrow) and the white matter lesion (red arrow). Isodose lines are same as in Fig 1.

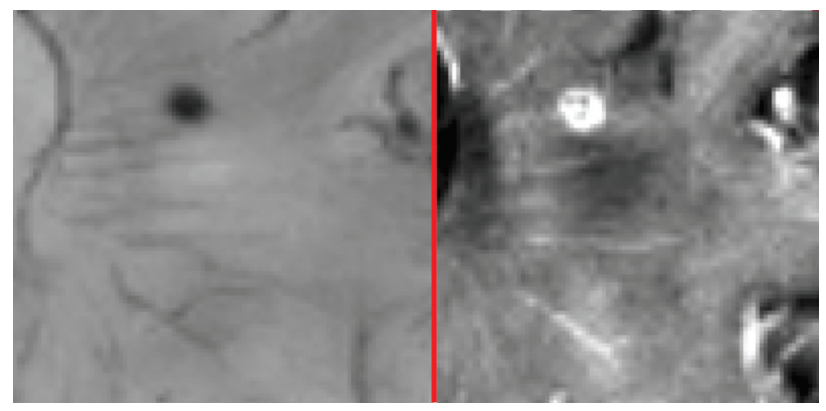

FIG 4. Zoomed-in view of Fig 3 (within the white box in Fig 3). Venous vasculature is seen through the suspected white matter lesion.

to look at the effect of anticoagulants. Certain studies have already shown that the appearance of microbleeds in other disease states could be a contraindication for the use of anticoagulants, ${ }^{35}$ and these findings suggest strategies attempting to limit radiation injury using antiplatelet agents or anticoagulants in this patient population should be evaluated cautiously. The disappearance of microbleeds between visits could not be considered imaging artifacts or due to true resolution as discussed by Yates et al. ${ }^{36}$

In addition to venous vasculature being present in high-dose regions, veins within the white matter lesions with high doses can be observed as shown in Fig 4. This is a common finding in MS and acute disseminated encephalomyelitis. ${ }^{37}$ The white matter lesions have been reported previously, ${ }^{30,31,38}$ with reports of cognitive decline. A recent communication has shown that a 43-yearold patient developed similar MS-type lesions following XRT. ${ }^{39}$ In MS, these lesions have been shown to have an immune response that could be indicative of neuroinflammation. The ability to show that these lesions have venules running through them suggests that further studies are warranted to test this hypothesis of neuroinflammation as a mediator of late radiation effects. Supporting this finding was the detection of FLAIR hyperintensities coupled with the low $\mathrm{R}_{2}^{*}$ values, which could indicate demyelination, though the white matter signal changes could not be pathologically confirmed as demyelinating. Neuroinflammation as a mediator of late radiation cerebral effects and as a potential therapeutic target is an area of active investigation, ${ }^{32}$ and these findings suggest imaging biomarkers such as SWI and $\mathrm{R}_{2}{ }^{*}$ might be useful tools for noninvasive monitoring of neuroinflammatory processes.
Additionally, the high $\mathrm{R}_{2}^{*}$ can help distinguish microbleeds and small venules that have much lower $\mathrm{R}_{2}{ }^{*}$ values $\left(20-40\right.$ seconds $\left.^{-1}\right)$. The halo effect and large susceptibility value of the microbleeds on QSM as shown in Fig 1 could lead to a reduced burden for neuroradiologists when detecting microbleeds using automated methods.

A limitation of this study is the small number of participants and an inability to acquire follow-up imaging for all patients. This preliminary experience illustrates the feasibility of the technique in this population and suggests that a study of a larger cohort of patients with this imaging technique may be warranted.

Another limitation of SWI techniques, in general, is that titanium clips used following surgery result in blooming artifacts on postprocessed images. The artifacts are due to the magnetic field perturbation due to these clips causing the signal to decay at a much higher rate, resulting in more distortions with lengthened TEs. These artifacts may lead to being unable to identify microbleeds in tissue close to the skull. Finally, SWI is limited in its ability to view the arterioles; however, Bian et $\mathrm{al}^{40}$ have shown that arteries and veins can be imaged in the same acquisition. This method could also decrease false-positives and improve microbleed detection, and it would also be beneficial in observing damage to the arterioles.

\section{CONCLUSIONS}

This work is a preliminary study examining the long-term effects of radiation therapy on patients treated for benign or low-grade neoplasms using ultra-high-field MR imaging. This study presented the potential of microbleeds in patients treated with XRT alone; the increased ability to detect microbleeds with ultra-highfield MR imaging with the use of SWI, $\mathrm{R}_{2}{ }^{*}$, and QSM; and the potential for white matter lesions in the high-dose area. The results presented in this study warrant further investigation in a larger patient cohort because these could have wide-ranging consequences in the long-term management of these patients.

Disclosures: Jean-Guy Belliveau—RELATED: Grant: London Regional Cancer Program Catalyst Grant, Comments: also, Canada Research Chairs Program, Canada Foundation for Innovation. Glenn S. Bauman-UNRELATED: Grants/Grants Pending: Canadian Institutes of Health Research/Ontario Institute for Cancer Research, Comments: support prostate cancer research. Keng Yeow Tay—RELATED: Grant: London Regional Cancer Program Catalyst Grant, Comments: London Regional Cancer Program Catalyst Grant, Canada Research Chairs Program, Canada Foundation for Innovation. Ravi S. Menon—RELATED: Grant: London Regional Cancer Program internal competition; UNRELATED: Payment for Lectures Including Service on Speakers Bureaus: Siemens; Patents (Planned, Pending or Issued): Siemens, Comments: sale of patent to Siemens in 2015.

\section{REFERENCES}

1. Lawrence YR, Li XA, el Naqa I, et al. Radiation dose-volume effects in the brain. Int J Radiat Oncol Biol Phys 2010;76:S20-27 CrossRef Medline

2. Monje ML, Dietrich J. Cognitive side effects of cancer therapy dem- 
onstrate a functional role for adult neurogenesis. Behav Brain Res 2012;227:376-79 CrossRef Medline

3. Monje ML. Cranial radiation therapy and damage to hippocampal neurogenesis. Dev Disabil Res Rev 2008;14:238-42 CrossRef Medline

4. Fink JR, Born D, Chamberlain MC. Radiation necrosis: relevance with respect to treatment of primary and secondary brain tumors. Curr Neurol Neurosci Rep 2012;12:276-85 CrossRef Medline

5. Rahmathulla G, Marko NF, Weil RJ. Cerebral radiation necrosis: a review of the pathobiology, diagnosis and management considerations. J Clin Neurosci 2013;20:485-502 CrossRef Medline

6. Levin VA, Bidaut L, Hou P, et al. Randomized double-blind placebocontrolled trial of bevacizumab therapy for radiation necrosis of the central nervous system. Int J Radiat Oncol Biol Phys 2011;79: 1487-95 CrossRef Medline

7. Moravan MJ, Olschowka JA, Williams JP, et al. Cranial irradiation leads to acute and persistent neuroinflammation with delayed increases in T-cell infiltration and CD11c expression in C57BL/6 mouse brain. Radiat Res 2011;176:459-73 CrossRef Medline

8. Ballesteros-Zebadúa P, Chavarria A, Celis MA, et al. Radiation-induced neuroinflammation and radiation somnolence syndrome. CNS Neurol Disord Drug Targets 2012;11:937-49 CrossRef Medline

9. Lupo JM, Chuang CF, Chang SM, et al. 7-Tesla susceptibilityweighted imaging to assess the effects of radiotherapy on normalappearing brain in patients with glioma. Int J Radiat Oncol Biol Phys 2012;82:e493-500 CrossRef Medline

10. Tanino T, Kanasaki Y, Tahara T, et al. Radiation induced microbleeds after cranial irradiation: evaluation by phase-sensitive magnetic resonance imaging with 3.0 Tesla. Yonago Acta Med 2013;56: 7-12 Medline

11. Warring DJ. Cerebral Microbleeds: Pathophysiology to Clinical Practice. Cambridge: Cambridge University Press; 2011

12. Gaensler E, Dillon W, Edwards M, et al. Radiation-induced telangiectasia in the brain simulates cryptic vascular malformations at MR imaging. Radiology 1994;193:629-36 CrossRef Medline

13. Charidimou A, Werring DJ. Cerebral microbleeds and cognition in cerebrovascular disease: an update. J Neurol Sci 2012;322:50-55 CrossRef Medline

14. Cordonnier C. Brain microbleeds. Pract Neurol 2010;10:94-100 CrossRef Medline

15. Bian W, Hess CP, Chang SM, et al. Susceptibility-weighted MR imaging of radiation therapy-induced cerebral microbleeds in patients with glioma: a comparison between 3T and 7T. Neuroradiology 2014;56:91-96 CrossRef Medline

16. Vernooij MW, Ikram MA, Wielopolski PA, et al. Cerebral microbleeds: accelerated 3D T2*-weighted GRE MR imaging versus conventional 2D T2* ${ }^{*}$ weighted GRE MR imaging for detection. $R a$ diology 2008;248:272-77 CrossRef Medline

17. Liu J, Liu T, Rochefort L De, et al. Morphology enabled dipole inversion for quantitative susceptibility mapping using structural consistency between the magnitude image and the susceptibility map. Neuroimage 2012;59:2560-68 CrossRef Medline

18. Liu T, Surapaneni K, Lou M, et al. Cerebral microbleeds: burden assessment by using quantitative susceptibility mapping. Radiology 2012;262:269-78 CrossRef Medline

19. Langkammer C, Liu T, Khalil M. Quantitative susceptibility mapping in multiple sclerosis. Radiology 2013;267:551-59 CrossRef Medline

20. Wisnieff C, Ramanan S, Olesik J, et al. Quantitative susceptibility mapping (QSM) of white matter multiple sclerosis lesions: interpreting positive susceptibility and the presence of iron. Magn Reson Med 2015;74:564-70 CrossRef Medline

21. Reichenbach JR, Barth M, Haacke EM, et al. High-resolution MR venography at 3.0 Tesla. J Comput Assist Tomogr 2000;24:949-57 CrossRef Medline
22. Lupo JM, Molinaro AM, Essock-Burns E, et al. The effects of antiangiogenic therapy on the formation of radiation-induced microbleeds in normal brain tissue of patients with glioma. Neuro Oncol 2016;18:87-95 CrossRef Medline

23. Na A, Haghigi N, Drummond KJ. Cerebral radiation necrosis. Asia Pac J Clin Oncol 2014;10:11-21 CrossRef Medline

24. Koppelmans V, Vernooij MW, Boogerd W, et al. Prevalence of cerebral small-vessel disease in long-term breast cancer survivors exposed to both adjuvant radiotherapy and chemotherapy. $\mathrm{J} \mathrm{Clin} \mathrm{On}$ col 2015;33:588-93 CrossRef Medline

25. de Rochefort L, Liu T, Kressler B, et al. Quantitative susceptibility map reconstruction from MR phase data using Bayesian regularization: validation and application to brain imaging. Magn Reson Med 2010;63: 194-206 CrossRef Medline

26. Yablonskiy DA, Sukstanskii AL, Luo J, et al. Voxel spread function method for correction of magnetic field inhomogeneity effects in quantitative gradient-echo-based MRI. Magn Reson Med 2013;70: 1283-92 CrossRef Medline

27. Jenkinson M, Smith SM. A global optimization method for robust affine registration of brain images. Med Imaging Anal 2001;5:143-56 CrossRef Medline

28. Deasy JO, Blanco AI, Clark VH. CERR: a computational environment for radiotherapy research. Med Phys 2003;30:979-85 CrossRef Medline

29. Ibáñez L, Schroeder W, Ng L, et al; Insight Software Consortium. The ITK Software Guide. August 21, 2003. https://www.sci.utah.edu/ publications/ibanez03/ItkSoftwareGuide.pdf. Accessed August 2015

30. Rane N, Quaghebeur G. CNS effects following the treatment of malignancy. Clin Radiol 2012;67:61-68 CrossRef Medline

31. Szerlip N, Rutter C, Ram N, et al. Factors impacting volumetric white matter changes following whole brain radiation therapy. J Neurooncol 2011;103:111-19 CrossRef Medline

32. Greene-Schloesser DM, Moore E, Robbins ME. Molecular pathways: radiation-induced cognitive impairment. Clin Cancer Res 2013;19: 2294-300 CrossRef Medline

33. Plummer C, Henderson RD, O’Sullivan JD, et al. Ischemic stroke and transient ischemic attack after head and neck radiotherapy: a review. Stroke 2011;42:2410-18 CrossRef Medline

34. Martinez-Ramirez S, Greenberg SM, Viswanathan A. Cerebral microbleeds: overview and implications in cognitive impairment. Alzheimers Res Ther 2014;6:33 CrossRef Medline

35. Haley KE, Greenberg SM, Gurol ME. Cerebral microbleeds and macrobleeds: should they influence our recommendations for antithrombotic therapies? Curr Cardiol Rep 2013;15:425 CrossRef Medline

36. Yates PA, Villemagne VL, Ellis KA, et al. Cerebral microbleeds: a review of clinical, genetic, and neuroimaging associations. Front Neurol 2014;4:205 CrossRef Medline

37. Quinn MP, Kremenchutzky M, Menon RS. Venocentric lesions: an MRI marker of MS? Front Neurol 2013;4:98 CrossRef Medline

38. Armstrong CL, Gyato K, Awadalla AW, et al. A critical review of the clinical effects of therapeutic irradiation damage to the brain: the roots of controversy. Neuropsychol Rev 2004;14:65-86 CrossRef Medline

39. Shaygannejad V, Zare M, Maghzi H, et al. Brain radiation and possible presentation of multiple sclerosis. J Res Med Sci 2013;18(suppl 1):S93-95 Medline

40. Bian W, Banerjee S, Kelly DA, et al. Simultaneous imaging of radiation-induced cerebral microbleeds, arteries and veins, using a multiple gradient echo sequence at 7 Tesla. J Magn Reson Imaging 2015; 42:269-79 CrossRef Medline 